\title{
Energy Conservation Framework
}

\section{An Integrative Framework for Energy Conservation Planning, Policy, and Strategy}

By Jack Edelstein, Ph.D.' and Michael Shriberg, Ph.D. ${ }^{2}$

\begin{abstract}
The quickest, cheapest, and most effective way to reduce the environmental impacts of energy usage is to conserve, i.e., to consume less energy. However, one potential pathway to reduce energy usage-efficiency-has become dominant over all other forms of energy conservation. Among the reasons for the dominance of efficiency are the narrowness and fuzziness in our understanding of what conservation actually means, and in particular the confusion and conflation between conservation and efficiency.

We define conservational as reducing the environmental footprint of energy generation or consumption relative to the preconservation state. This paper clarifies this concept of conservation through offering a four-dimensional integrative framework. Conservation is, within this framework, an "end," with four "means" to get there: 1.) reducing demand through behavioral changes that decrease actual consumption; 2.) eliminating waste through behavioral and technological changes that remove energy usage, which engenders no gain in utility; 3.) substituting for higher impact methods of using energy with lower impact methods through behavioral and technological alterations of fundamental approaches and technologies; and 4.) using energy more efficiently through technological improvements to existing approaches.

The integrative framework is presented at three levels of implementation-individual household, commercial building, and institutional-to demonstrate the power of an integrative, holistic approach to conservation. Our assertion is that the real progress toward reducing the environmental footprint of energy usage, as well as the interrelated social and economic impacts, comes from carefully analyzing and balancing the full mix of potential conservation strategies, including, but not limited to, efficiency.
\end{abstract}

\section{Introduction}

If the goal is to reduce the environmental footprint of our energy usage, then a strategy that emphasizes reduced energy consumption is less costly and has fewer negative consequences than a strategy of producing and using new energy, regardless of the energy source or the degree of efficiency.
This position represents a consensus view in the theoretical literature as well as, increasingly, among energy management practitioners. ${ }^{1-4}$ Despite this consensus, the focus of energy policies, strategies, and project funding reveals a very strong bias toward using and producing energy more efficiently (efficiency), rather than reducing energy consumption (conservation). ${ }^{\text {5-9 }}$ Why has conservation, given its strong theoretical and practical pedigree, not been more widely embraced by policy makers, institutions, practitioners, academics, and homeowners?

While there are many reasons for the dominance of efficiency over conservationincluding cultural, political, and technological factors-one potential explanation stems

'Energy Conservation Strategies LLC, Ann Arbor, Michigan.

${ }^{2}$ Graham Environmental Sustainability Institute, Program in the Environment, University of Michigan, Ann Arbor, Michigan. 
from the narrowness and fuzziness in our thinking about what conservation means and how it is different from efficiency. The two concepts require deeper differentiation and more structured thinking in order to be effectively balanced and operationalized. This definitional fuzziness has more than intellectual consequences: efficiency gains do not always lead to reduced consumption and may in fact lead to the opposite outcome, as the rebound effect and related economic theories demonstrate. ${ }^{10-13}$

To more clearly understand conservation and to maximize its application, we present a four-dimensional integrative framework for defining conservation and its application, based in part on our experience with the Planet Blue program for energy conservation (http://www. planetblue.umich.edu/) at the University of Michigan. Examined in terms of the implications of decision making by individual homeowners, multi-occupant buildings, and institutions, this framework places efficiency as one strategy to conserve energy rather than as an end goal in and of itself. Our assertion is that the real progress toward reducing the environmental footprint of energy usage, as well as the interrelated social and economic impacts, comes from carefully analyzing and balancing the full mix of potential conservation strategies, including, but not limited to, efficiency.

\section{Efficiency's Dominance}

There are strong cultural impediments to conservation that are embedded in values and norms, such as the widely held beliefs (particularly in Western societies) that growth is a desirable social goal, ${ }^{6}$ that energy is an inalienable right ${ }^{2}$, that the energy market is rational and will correct for inefficiencies, and that conservation equates with deprivation. ${ }^{14}$ Conservation and efficiency have battled for supremacy in American ideology for at least a century. The deeply held notions of frugality and simplicity stem from such American icons as Benjamin Franklin ("waste not, want not"), Henry David Thoreau, and the classic images of self-sufficient Yankees or pioneers. This conservation-oriented ethic was most visibly enacted last century during the world wars (although the social goals were quite different) and then again during the energy crisis of the 1970s. ${ }^{15}$ However, the concept and

Table 1. Costs of the Four Components of an Integrative Energy Conservation Framework

\begin{tabular}{|c|c|c|c|c|}
\hline & Reduce demand & Eliminate waste & Substitute & Maximize efficiency \\
\hline Cost & Zero & Low & Moderate & High \\
\hline
\end{tabular}

social goal of efficiency-not just in energy but in business and social policy writ largeappears to have won the battle to dominate American culture, professional practice, and academic research. This trend has become more prominent since President Carter's largely derided pleas for conservation and an ethic of self-sufficiency. ${ }^{6}$ Conservation has come to have a negative connotation associated with sacrifice and discomfort that runs counter to progress. ${ }^{15}$ Meanwhile, efficiency, and the growth in GDP that goes along with it, is now the largely unquestioned policy and social goal in energy policy and beyond. Efficiency has an overwhelmingly positive connotation associated with economic and social progress. Even in academic circles, research on energy conservation behavior is being minimized in favor of the technological, efficiency-oriented approach. ${ }^{9}$ Policy makers, analysts, and practitioners emphasize technological improve- ments over behavioral, ethical, and more socially challenging notions of conservation. For example, the New York Times recently reported that "Governments around the world that used to promote energy conservation are shifting their focus toward energy efficiency as a way to curb global warming without constraining economic growth." 14

As this dominance of efficiency has progressed, the terms conservation and efficiency have been confused and conflated, sometimes even by conservation advocates who believe their goals have a better chance of being actualized when tied to the dominant concept of efficiency. For example, the assertion that "...increased energy efficiency could lead to halving of per capita energy requirements in the industrialized world" disregards the fact that increased efficiency in the United States over the past 40 years has coincided with a consistent annual increase in energy consumption. Similarly, the claim that "the U.S. building sector can produce $30-50 \%$ of its energy needs by more efficient use of energy, i.e., by conservation," ${ }^{17}$ directly conflates the two terms. The contention that "energy conservation in [the] building industry refers to replacement or retrofit of old and inefficient equipment with new energy-efficient technologies" 18 also confounds the terms. Even the renowned energy analyst Amory Lovins seems to confuse the terminology, or not be concerned about the distinction, when he asserts that "...for me, efficiency and conservation is the same thing." ${ }^{\prime 9}$ This analytical fuzziness manifests itself in institutional and governmental policy as well as individual behavior.

\section{An Integrative Framework for Defining Ways To Conserve Energy}

A solid yet broad conceptual framework for energy conservation can help advance both practice and theory by providing specific terminology, parameters, and benchmarks for planning, implementing, and measuring across the full spectrum of the conservation doctrine. Our framework offers insight for integrating technological systems and individual behaviors, thereby enabling the development of a more organic approach that will result in enhanced energy conservation outcomes. We define conserving as reducing the environmental footprint of energy generation or consumption relative to the preconservation state. Conservation is, within this framework, an "end," with four "means" to get there. Each of the four conservation strategies is associated with characteristic behavioral and/or technology choices and a unique life-cycle cost (Table 1).

1. Decreasing demand. Demand reductions involve conscious behavioral choices to reduce usage of the product or output derived from an energy resource despite the loss of utility. Therefore, this parameter typically involves psychologically based initiatives that encourage individuals or institutions to alter consumption patterns even though doing so involves some sacrifice. The direct costs for reducing demand in this way are typically minimal.

2. Eliminating waste. Wasting is the act of consuming resources without deriving any value. This is distinguished from 
excess, which involves some marginal utility. Waste is exacerbated when the perpetrator of the waste feels no consequence, e.g., a college student or an office worker who does not pay (directly) for the utilities used by his or her institution. Therefore, the consequences of wasteful behavior are hidden. Eliminating waste is typically both a behavioral and technological action, involving no sacrifice or loss of utility but reliant on education and expertise. Reducing or eliminating waste is generally a low-cost strategy since there is no value lost.

3. Substituting less resource-intense alternatives. Substitution means switching a current behavior or method with one that delivers similar benefits in ways that result in a smaller footprint. This substitute parameter can be both behavioral, when the demand side is being substituted, or technological, when the supply element is being substituted. The expense of substituting is variable; it is generally high when it involves an advanced technology component (e.g., solar collectors), but it can also be low when the changes are behavioral. The key distinguishing feature of substitution is that the practice or technology is fundamentally altered, not just reduced or improved.

4. Maximizing efficiency. Increasing efficiency of production or consumption means using fewer resources to create a given unit of output, or receiving more output for the same level of input. This standard way of thinking about "saving energy" is largely technological and generally requires significant upfront investment.

These four strategies form a continuum in which the boundaries are fluid for certain actions and issues and are dependent upon the assumptions about actors, benefits, and system boundaries. For example, home weatherization is a strategy to eliminate waste from the perspective of the homeowner and the home itself, since heating or cooling that leaks out of the home provides no utility to the homeowner. From the perspective of furnace output, weatherization is an efficiency measure since increases in weatherization lead to increased heating or cooling per unit of energy consumed by the furnace. Therefore, for analyses to be use-

Table 2. Integrative Energy Conservation Framework at the Individual Level: Showering Example

\begin{tabular}{|c|c|c|c|c|}
\hline Water & Reduce demand & Eliminate waste & Substitute & Maximize efficiency \\
\hline Lower flow rate & $\begin{array}{c}\text { Shut off when } \\
\text { lathering } \\
\text { Fix leaKs }\end{array}$ & Sponge bath & $\begin{array}{c}\text { Low flow } \\
\text { shower head }\end{array}$ \\
\hline $\begin{array}{c}\text { Natural } \\
\text { Gas }\end{array}$ & $\begin{array}{c}\text { Lower the water } \\
\text { temperature }\end{array}$ & $\begin{array}{c}\text { Turn down when } \\
\text { not being used }\end{array}$ & Solar & $\begin{array}{c}\text { High-efficiency hot } \\
\text { water heater }\end{array}$ \\
\hline
\end{tabular}

ful, they must pay careful attention to the boundaries of the system as well as the perspective of the analyst.

\section{Applying the framework at the homeowner level}

Applying the Integrative Energy Conservation Framework at the individual level in situations in which the individual has a relatively high degree of control over the amount of resource consumption (e.g., a homeowner) reveals the usefulness of assessing conservation options. We use the example of showering (Table 2) because the possible decisions are easily comprehensible, and because it allows us to apply the framework to water as well as energy (e.g., natural gas) to heat the water. The principles for energy conservation apply equally well to other resources such as water. This example does not delve into the life-cycle cost of production and disposal of the shower components (e.g., the water heater, shower stall or tub, shower head, and faucets, etc.).

Options to decrease demand when showering include reducing the shower time or number of showers taken, lowering the flow rate (i.e., accepting less water), or accepting less hot water by lowering the water temperature, thereby reducing the amount of energy used in heating the water. In each case, the solution is entirely behavioral and involves some sacrifice of utility.

Potential actions to reduce or eliminate waste when showering include fixing a leaking showerhead, turning off the shower while soaping up (e.g., when the water is not serving a need), or adjusting the water heater thermostat to match actual usage of hot water, i.e., reducing the amount of energy devoted to heating water that does not actually get used. These activities do not involve any loss of utility.

A simple example for substitution of showering is taking a sponge bath, thereby drasti- cally reducing the use of water, along with the energy required to move and heat it. Another example is substituting solar hot water collectors for a conventional fossilfuel based water tank. The sponge bath approach is relatively low cost and includes both behavioral as well as technological elements, while the solar panel solution is more expensive and technologically oriented. Both require a change in approach to achieve the same goal.

Improved efficiency when showering can be achieved by installing a low-flow showerhead (assuming shower duration and satisfaction stay constant), which also results in less energy used to heat the smaller volume of water. Similarly, even more energy reduction can be attained by replacing a lowerefficiency with a higher-efficiency hot water heater. These approaches provide the same service for less energy through technological improvements.

\section{Applying the framework at the multi-occupant building level}

Applying the integrative framework at the multi-occupant building level (Table 3) offers insights into combining systemsbased solutions with individually oriented approaches. Too often, facility managers operate the building's mechanical systems so as to minimize or even eliminate occupant complaints, rather than to seek the more challenging objective of systematically balancing occupant comfort with lower resource consumption. This framework can help counteract this tendency.

Examples of conserving energy through decreasing demand in buildings and facilities include accepting lower temperatures in winter and higher temperatures in summer and shortening building operating hours during periods of less intensive use (e.g., during holidays). Behavior-based efforts to reduce demand in operating the building may involve some loss of utility among 
Table 3. Integrative Energy Conservation Framework at the Building Level

\begin{tabular}{|c|c|c|c|c|}
\hline & Reduce demand & Eliminate waste & $\begin{array}{c}\text { Substitute } \\
\text { (smaller } \\
\text { footprint) }\end{array}$ & Maximize efficiency \\
\hline HVAC & $\begin{array}{l}\text { Accept lower } \\
\text { temperature in } \\
\text { winter, higher in } \\
\text { summer } \\
\text { Shorten building } \\
\text { hours } \\
\text { Close down } \\
\text { portion of building } \\
\text { during slow times }\end{array}$ & $\begin{array}{c}\text { Ongoing } \\
\text { preventative } \\
\text { maintenance } \\
\text { Tighten building } \\
\text { envelope } \\
\text { Schedule HVAC } \\
\text { to match actual } \\
\text { building hours }\end{array}$ & $\begin{array}{l}\text { Wear more } \\
\text { (less) clothing } \\
\text { during winter } \\
\text { (summer) } \\
\text { months } \\
\text { Use fan or } \\
\text { space heater }\end{array}$ & $\begin{array}{l}\text { Upgrade equipment } \\
\text { Install new } \\
\text { equipment }\end{array}$ \\
\hline Lighting & $\begin{array}{l}\text { Use natural light } \\
\text { Eliminate some } \\
\text { ceiling light fixtures }\end{array}$ & $\begin{array}{l}\text { Turn lights off } \\
\text { when not in use } \\
\text { Occupancy } \\
\text { sensors }\end{array}$ & $\begin{array}{c}\text { Use task } \\
\text { lamp instead } \\
\text { of overhead } \\
\text { lights }\end{array}$ & Use CFL or LED bulbs \\
\hline Equipment & $\begin{array}{l}\text { Share equipment } \\
\text { among units }\end{array}$ & $\begin{array}{l}\text { Apply power- } \\
\text { save mode } \\
\text { Use motion- } \\
\text { sensing power } \\
\text { strip } \\
\text { Shut down when } \\
\text { facility is } \\
\text { unoccupied }\end{array}$ & & $\begin{array}{l}\text { Purchase Energy } \\
\text { Star equipment }\end{array}$ \\
\hline Restroom & $\begin{array}{l}\text { Avoid flushing after } \\
\text { smaller output }\end{array}$ & $\begin{array}{l}\text { Repair leaks } \\
\text { Insulate pipes }\end{array}$ & & $\begin{array}{l}\text { Low-flow aerators } \\
\text { Waterless urinals } \\
\text { Dual-flush handles }\end{array}$ \\
\hline
\end{tabular}

Table 4. Integrative Energy Conservation Framework at the Institutional Level: Higher Education Example

\begin{tabular}{|c|c|c|c|c|}
\hline & Reduce demand & Eliminate waste & Substitute & Maximize efficiency \\
\hline $\begin{array}{c}\text { Institutional } \\
\text { Policy/ } \\
\text { Program }\end{array}$ & $\begin{array}{c}\text { Behavioral } \\
\text { change } \\
\text { programs }\end{array}$ & $\begin{array}{c}\text { Vampire slaying } \\
\text { campaign } \\
\text { Computer shutoff } \\
\text { program }\end{array}$ & $\begin{array}{c}\text { Renewable } \\
\text { energy } \\
\text { investments }\end{array}$ & $\begin{array}{c}\text { Green building } \\
\text { policy }\end{array}$ \\
$\begin{array}{c}\text { Efficiency revolving } \\
\text { loan funds }\end{array}$ \\
\hline
\end{tabular}

occupants, arising from decisions made by the facility manager or business administrator.

Although we have a great deal of data about how much energy is consumed by various societal functions (e.g., transportation, food production, facility operations), there is surprisingly little data about how much energy is wasted in buildings. Nonetheless, even a casual observation of almost any building facility will reveal various levels of waste (e.g., lights on in empty rooms, HVAC systems operating when the building is unoccupied, and dripping water faucets). The sources of this waste vary from technological to behavioral, as do the potential solutions.
Substitution is perhaps the most challenging of the four elements for buildings, yet it also offers the most opportunities for creative solutions. For example, using a desk lamp instead of overhead lights can reduce the amount of energy used for lighting by 90 percent. This technological and behavioral switch is probably the most effective way that an individual can reduce energy use in the office. Other examples include wearing more clothing during the winter-i.e., substituting thermal layers of clothing for higher heat settings - and substituting a fan or space heater for a change in the heating or air-conditioning level. While the traditional approach in the energy conservation com- munity is to shun the use of fans or space heaters, the strategy of selectively substituting these accessories for increased HVAC may actually contribute to energy reduction, particularly in light of the fact that there is a very high correlation among those who complain about being cold in the winter and hot during the summer. ${ }^{20}$

Efficiency improvements typically involve upgrading or replacing equipment, ranging from minor system modifications such as exchanging standard serpentine belts with cog-belts, to larger investments such as replacing an absorption chiller with a centrifugal chiller. These technologically oriented solutions tend to absorb the most time and resources of energy professionals.

\section{Applying the framework at the institutional level}

Using the example of an institution of higher education (Table 4), this framework can help categorize and assess the many programs and policies relating to conservation at the institutional level.

Reducing demand in a higher education institution typically involves investing in a behavioral change program that attempts to influence decisions and choices. For example, according to the Association for the Advancement of Sustainability in Higher Education, ${ }^{21}$ over 50 colleges and universities have Eco-Rep programs in which students and/or staff attempt to model environmentally responsible practices that reduce demand for energy (and other resources). Many others have simple signs encouraging students to take shorter showers or to lower lighting levels, for example. A more comprehensive approach to reducing demand would involve shutting down buildings or entire institutions during certain periods (e.g., winter break). While the effectiveness of these campaigns varies widely, the institutional investments tend to be small when compared with maximizing efficiency or resource substitution. There are typically no formal policies, but rather informational or motivational campaigns.

Similar to reducing demand, institutions of higher education tend to invest in eliminating waste through individual campaigns or initiatives. These initiatives may even be started and maintained by students as 
opposed to institutions. The resultant behavioral changes involve no sacrifice since the activity being encouraged is not producing any value, distinguishing them from reducing demand. For example, vampire powerdefined as power used by electronic devices when they are plugged in but not in use-is drawing increasing attention from cleanenergy advocates. Campaigns to ensure that these devices are left unplugged ("slay the vampires") are being run by students on many campuses. Other campuses are focused on educating students and faculty to turn off computers and monitors when not in use, particularly overnight. Reducing waste in lighting can be achieved via coordinated efforts to leave rooms dark when not in use. However, investments in these initiatives tend to be scattered and small unless they are tied specifically to procurement waste reduction initiatives.

A familiar institutionalized way to conserve energy in higher education is through policies and investments that substitute renewable energy for fossil fuels. Whether it is installing solar panels or wind turbines on campuses, committing to a renewable energy standard, or purchasing Renewable Energy Certificates (RECs), this substitution often receives the most attention and resources. This strategy is often the focus of student activism and administrative public relations efforts.

The most common way to conserve energy at the institutional level in higher education, as elsewhere, is through investments in efficiency. The proliferation of green building policies (typically using a LEED standard), energy efficiency loan funds, and institutional building retrofits, focus almost exclusively on this parameter. Investments in these technologically based efforts dominate institutional efforts and are often implemented through formal policy and programs.

\section{Conclusion}

Under the assumption that the quickest and most cost-effective way to reduce our impacts from fossil fuels is through avoiding the usage of nonrenewable energy, we define energy conservation from an integrative perspective. Our assertion is that this integrative, systemic approach is more effective in promoting reductions in energy usage (and usage of other resources) than policies and strategies that focus on efficiency only. The current dominance of efficiency results in capital-intensive and technology-based solutions, disempowering individuals and institutions by encouraging them to overlook the more behavioraloriented options for energy conservation. For example, replacing an old furnace with a more efficient one may not be as effective as simpler measures to reduce demand, such as shortening the building's operating hours. For efficiency measures to achieve a maximum impact they should be combined with the other elements of the integrative framework.

The endorsement of an integrative approach to energy conservation should not be misinterpreted as an argument against efficiency, for efficiency has a central role to play in the goal of reduced energy consumption. Rather, any effort to conserve energy-whether at the individual, building, or institutional level-should examine all four elements of the conservation framework and select the specific strategy mix that matches the particular situation. The strength in this definitional approach to conservation lies in the clarity with which decision makers can analyze potential options to achieve an end goal of reducing the environmental footprint of energy usage.

\section{Acknowledgments}

The authors wish to thank David Gard and Andrew Horning for their thoughtful reviews, and Jennifer Geiger for her research and analytical acumen.

\section{Author Disclosure Statement}

No conflicting financial interests exist.

\section{References}

1.Coltrane S, Archer D, and Aronson E. The social-psychological foundations of successful energy conservation. Energy Policy 1986;1(4):133-148.

2. Harris J, Diamond R, Iyer M, et al.

Towards a sustainable energy balance: Progressive efficiency and the return of energy conservation. Energy Efficiency 2008;1:175188.

3. Kollmuss A, and Agyeman J. Mind the gap: Why do people act environmentally and what are the barriers to pro-envi- ronmental behavior? Environ Educ Res 2002;8(3):239-260.

4. Winet RA, and Ester P. Behavioral science and energy conservation: Conceptualizations, strategies, outcomes, energy policy applications. LEcon Psychol 1983;3:203229.

5. Harris J, Diamond R, Payne C, et al. Don't supersize me! Toward a policy of consumption-based energy efficiency. Proceedings of 2006 ACEEE Summer Study on Energy Efficiency in Buildings. American Council for an Energy-Efficient Economy, Asilomar, CA.

6. Herring H. Energy efficiency-A critical view. Energy 2006;31:10-20.

7. Princen T. The Logic of Sufficiency. MIT

Press, Cambridge, MA, 2005.

8. Spence A, and Pidgeon N. Psychology, climate change \& sustainable behaviour. Environment: Science and Policy for Sustainable Development 2009;1(6):8-18.

9. Wilhite H, Shove E, Lutzenhiser L, et al.

The legacy of twenty years of energy demand management: We know more about individual behaviour but next to nothing about demand. In Jochem E, Sathaye D, and Bouile D (eds.). Society, Behavior, and Climate Change Mitigation. Kluwer Academic Publishers, Dordrecht, the Netherlands, 2000.

10. Alcott B. Jevons' paradox. Ecol Econ 2005;54(1):9-21.

11. Greening LA, Greene DL, and Difiglio

C. Energy efficiency and consumption-the rebound effect-a survey. Energy Policy 2000;28:389-401.

12. Khazzoom JD. Economic implications of mandated efficiency in standards for household appliances. Energy Journal 1980;1(4):21-40.

13. Sorrel S. Jevons' Paradox revisited: The evidence for backfire from improved energy efficiency. Energy Policy 2009;37:1456-

1469.

14. Strauss MJ. Efficiency replaces conservation as the goal of energy saving policies. New York Times, 2007. http:// www.nytimes.com/2007/10/30/business/ worldbusiness/30iht-reneff.1.8110766.html (last accessed 5/12/2011).

15. Moezzi M. The predicament of efficiency. Proceedings of the 1998 ACEEE Summer Study on Energy Efficiency in Buildings. American Council for an Energy-Efficient Economy 1998;4:273-282. 16. Shippee G. Energy consumption and conservation psychology: A review and 
conceptual analysis. Environ Manage 1981;4(4):297-314.

17. Shama A. Energy conservation in US buildings: Solving the high potential/low adoption paradox from a behavioural perspective. Energy Policy 1983;11(2):148-167. 18. Yalcintas $M$, and Kaya A. Conservation vs. renewable energy: Case studies from $\mathrm{Ha}$ waii. Energy Policy 2009;37(8):3268-3273. 19. Lovins A. Morning Edition, All Things Considered. NPR, January 12, 2010.
20. Marans R, and Edelstein J. The human dimension of energy conservation \& sustainability: A case study of the University of Michigan's energy conservation program. J. Sustain. in Higher Educ 2010;11(1). 21. Association for the Advancement of Sustainability in Higher Education (AASHE). Peer to Peer Sustainability Outreach Campaigns. http://www.aashe.org/resources/peer-peer-sustainability-outreachcampaigns (last accessed 6/30/2011).
Address correspondence to: Michael Shriberg, Ph.D.

Graham Environmental

Sustainability Institute

University of Michigan

625 E. Liberty Street, Suite 300

Ann Arbor, MI 48104

Email: mshriber@umich.edu 